\title{
Cholinergic Excitation of Septohippocampal GABA But Not Cholinergic Neurons: Implications for Learning and Memory
}

\author{
Min Wu, ${ }^{1}$ Marya Shanabrough, ${ }^{2}$ Csaba Leranth, ${ }^{2,3}$ and Meenakshi Alrejaa ${ }^{1,3}$ \\ Departments of ${ }^{1}$ Psychiatry, ${ }^{2}$ Obstetrics and Gynecology, and ${ }^{3}$ Neurobiology, Yale University School of Medicine and the \\ Ribicoff Research Facilities, Connecticut Mental Health Center, New Haven, Connecticut 06508
}

The medial septum/diagonal band (MSDB), which gives rise to the septohippocampal pathway, is a critical locus for the mnemonic effects of muscarinic drugs. Infusion of muscarinic cholinergic agonists into the MSDB enhance learning and memory processes both in young and aged rats and produce a continuous theta rhythm in the hippocampus. Intraseptal muscarinic agonists also alleviate the amnesic syndrome produced by systemic administration of muscarinic receptor antagonists. It has been presumed, but not proven, that the cellular mechanisms underlying the effects of muscarinic agonists in the MSDB involve an excitation of septohippocampal cholinergic neurons and a subsequent increase in acetylcholine (ACh) release in the hippocampus. Using a novel fluorescent labeling technique to selectively visualize live septohippocampal cho- linergic neurons in rat brain slices, we have found that muscarinic agonists do not excite septohippocampal cholinergic neurons, instead they inhibit a subpopulation of cholinergic neurons. In contrast, unlabeled neurons, confirmed to be noncholinergic, septohippocampal GABA-type neurons using retrograde marking and double-labeling techniques, are profoundly excited by muscarine. Thus, the cognition-enhancing effects of muscarinic drugs in the MSDB cannot be attributed to an increase in hippocampal ACh release. Instead, disinhibitory mechanisms, caused by increased impulse flow in the septohippocampal GABAergic pathway, may underlie the cognitionenhancing effects of muscarinic agonists.

Key words: theta rhythm; 192lgG; p75 receptor; neurotrophin; acetylcholine; memory; cognition; disinhibition
Basic and clinical studies have long recognized the importance of cholinergic mechanisms in cognitive functioning (Givens and Sarter, 1997), and drugs that increase synaptic acetylcholine levels are currently the most used for the treatment of cognitive deficits associated with CNS disorders such as Alzheimer's disease, albeit, with limited effectiveness (Benzi and Moretti, 1998). The septohippocampal $(\mathrm{SH})$ pathway, which originates in the medial septum/diagonal band (MSDB) and shows progressive degeneration in Alzheimer's disease (Whitehouse et al., 1982), has specifically been implicated in cognitive mechanisms. Lesions of the fimbria-fornix, which conveys SH cholinergic (Lewis and Shute, 1967) and GABAergic fibers to the hippocampus (Kohler et al., 1984; Freund, 1989), interfere both with learning and memory tasks and with generation of the theta rhythm in rats (Brito and Brito, 1990). These deficits can be attenuated by grafting AChproducing cells to the hippocampus (Dunnett et al., 1982; Dickinson-Anson et al., 1998).

Cholinergic mechanisms operating within the MSDB are also critical for learning and memory. Thus, infusions of muscarinic agonists directly into the MSDB elicit continuous hippocampal theta (Monmaur and Breton, 1991; Lawson and Bland, 1993) and facilitate learning and memory-related behaviors both in young (Givens and Olton, 1990) and aged rats (Markowska et al., 1995). Intraseptal infusions of muscarinic agonists can also alleviate

\footnotetext{
Received Nov. 29, 1999; revised March 2, 2000; accepted March 6, 2000.

This work was supported by National Alliance for Research on Schizophrenia and Depression and National Institutes of Health Grants DA09797 to M.A. and NS26068 to C.L. We thank N. Margiotta for technical help and Leslie Rosello for help in manuscript preparation.

Correspondence should be addressed to Dr. Meenakshi Alreja, Department of Psychiatry, CMHC 335A, Yale University School of Medicine, 34 Park Street, New Haven, CT 06508. E-mail: Meenakshi.Alreja@yale.edu.

Copyright (C) 2000 Society for Neuroscience $0270-6474 / 00 / 203900-09 \$ 15.00 / 0$
}

systemic scopolamine-induced amnesia, suggesting that the MSDB is a critical locus for the mnemonic effects of muscarinic drugs (Givens and Olton, 1995).

In general, it is assumed that improvements in SH pathwayrelated learning and memory tasks occurs as a result of an increase in hippocampal ACh release (Monmaur and Breton, 1991; Givens and Olton, 1994, 1995; Apartis et al., 1998; Bland and Oddie, 1998; Dickinson-Anson et al., 1998). As such, it has been presumed that the memory-enhancing effects of intraseptalmuscarinic agonists occur because of increased firing of $\mathrm{SH}$ cholinergic neurons (Markowska et al., 1995; Givens and Sarter, 1997). These assumptions have been based on earlier studies that reported a muscarinic receptor-mediated increase in firing of $\mathrm{SH}$ neurons (Dutar et al., 1983; Lamour et al., 1984), which lead to the hypothesis that $\mathrm{ACh}$, via muscarinic receptors, has a positive feedback effect on SH cholinergic neurons (Dutar et al., 1983; Lamour et al., 1984; Segal, 1986). However, the SH neurons recorded from in these studies were presumed but not proven to be cholinergic. A small sample of cholinergic-type MSDB neurons $(n=3)$, classified using electrophysiological characteristics, were found to be inhibited by muscarine (Serafin et al., 1996). Additional effects of muscarine, such as a block of late afterhyperpolarization (Sim and Griffith, 1991) and decrease in glutamate transmission (Sim and Griffith, 1996) have also been reported in unidentified basal forebrain neurons. Effects of muscarinic agonists on identified septohippocampal cholinergic neurons have not been investigated.

In the present study, we used a novel fluorescent marker, Cy3-192IgG, to selectively label live rat SH cholinergic neurons and studied their response to cholinergic drugs using extracellular and whole-cell recordings in brain slices. Cy3-192IgG is prepared by conjugating the inert fluorochrome, $\mathrm{Cy} 3$, with an antibody 
against the p75 neurotrophin receptor. When injected intraventricularly, Cy3-192IgG retrogradely labels only p75 receptorexpressing neurons (Hartig et al., 1998), which in the MSDB are exclusively cholinergic (Batchelor et al., 1989; Sobreviela et al., 1994). The goal of this study was to determine whether identified $\mathrm{SH}$ cholinergic neurons are excited by their own neurotransmitter via muscarinic receptors.

\section{MATERIALS AND METHODS}

Retrograde labeling of septohippocampal neurons. Young adult male Sprague Dawley albino rats (14- to 21-d-old) were anesthetized using the following cocktail: ketamine, $75 \mathrm{mg} / \mathrm{kg}$; xylazine, $4 \mathrm{mg} / \mathrm{kg}$, and acepromazine, $0.075 \mathrm{mg} / \mathrm{kg}$. Retrograde labeling of septohippocampal neurons (SHNs) was performed by pressure injecting 50-100 nl of rhodamine-labeled fluorescent latex microspheres (Lumafluor, Naples, FL) at several sites within the hippocampus of 14- to 21-d-old rats using a glass micropipette (40-50 $\mu \mathrm{m}$ tip diameter). Rhodamine microspheres (0.02-0.2 $\mu \mathrm{m}$ diameter) show little diffusion and consequently produce small, sharply defined injection sites. Once transported back to neuronal somata, the label persists for at least 10 weeks in vivo and 1 year after fixation. Microspheres have been reported to possess no obvious cytotoxicity or phototoxicity, as assessed by intracellular recording and staining of retrogradely labeled cells in brain slice preparation (Katz et al., 1984). The stereotaxic coordinates were: anteroposterior, $-2.8,-1.4$, -2.8 ; lateral, $-4,-1.4,-2.8$; and ventral, $-5.8,-4.5,-3.5$ to $-6 \mathrm{~mm}$ track). Two or more days later, the injected rats were used to prepare brain slices. Injection sites were confirmed for each experiment.

Labeling of septohippocampal cholinergic neurons using Cy3-192IgG. In anesthetized rats $\mathrm{Cy} 3-192 \mathrm{IgG}(3-5 \mu \mathrm{l} ; 0.4 \mathrm{mg} / \mathrm{ml})$ was stereotaxically injected unilaterally or bilaterally into the lateral ventricle of each rat with a Hamilton syringe ( 22 gauge needle) at a rate of $0.5 \mu \mathrm{l} / \mathrm{min}$. The coordinates used were: $0.8 \mathrm{~mm}$ posterior from bregma, $1.2 \mathrm{~mm}$ lateral from midline, and 3-4 mm below the dura. Two to five days later, slices were prepared from Cy3-192IgG-injected rats and used for electrophysiological recordings. Recordings from unlabeled neurons were restricted to animals injected biventricularly.

Colocalization studies. Brain tissue taken from Cy3-192IgG-injected rats was immersion-fixed and, then, consecutive $50 \mu \mathrm{m}$ sections of the MSDB were cut on a Vibratome. Alternate sections were immunostained for either choline acetyltransferase (ChAT) or the calcium-binding protein, parvalbumin (Parv). For the ChAT immunoreaction, the sections were incubated in a rat-anti-ChAT primary antibody (1:5 dilution in PB; Boehringer Mannheim, Indianapolis, IN) overnight at room temperature. Subsequently, sections were incubated in rabbit anti-rat IgGfluorescein-labeled (1:100 in PB; Vector Laboratories, Burlingame, CA; FI4000) for $2 \mathrm{hr}$ at room temperature in the dark. For Parv, the sections were incubated in a rabbit anti-Parv (1:500 dilution in PB; gift of K. G. Baimbridge, Vancouver, Canada; overnight at room temperature) followed by goat anti-rabbit IgG-fluorescein (1:100 in PB; Vector Laboratories; FI1000; $2 \mathrm{hr}$ at room temperature in the dark).

Immunofluorescence was visualized under an Olympus BX50WI scope (Olympus Optical, Tokyo, Japan) using the appropriate filters for $\mathrm{Cy} 3$ and fluorescein. $\mathrm{Cy} 3$ appeared as granules within the cytoplasm of the cells, whereas the ChAT and Parv immunofluorescence was homogeneously distributed in the cells. This made it easy to confirm colocalization of the two substances in the same cell.

Slice preparation for electrophysiological recordings. Brain slices containing the MSDB were prepared from young adult male Sprague Dawley albino rats (2- to 4-weeks-old) using methods detailed previously (Alreja and Liu, 1996). Briefly, rats were anesthetized with chloral hydrate (400 $\mathrm{mg} / \mathrm{kg}$, i.p.) and killed by decapitation. The ACSF, $\mathrm{pH}$ 7.35-7.38, equilibrated with $95 \% \mathrm{O}_{2}$ and $5 \% \mathrm{CO}_{2}$, contained (in $\mathrm{mM}$ ): $\mathrm{NaCl}, 126 ; \mathrm{KCl}, 3$; $\mathrm{NaH}_{2} \mathrm{PO}_{4}, 1.25$; D-glucose, $10 ; \mathrm{NaHCO}_{3}, 25 ; \mathrm{CaCl}_{2}, 2$, and $\mathrm{MgSO}_{4}, 2$. After decapitation, the brain was removed and placed in a Petri dish containing ACSF and trimmed to yield a small block containing the MSDB. Coronal slices of $\sim 300 \mu \mathrm{m}$ thickness containing the MSDB were cut with a vibrating-knife microtome (Frederick Haer, Bowdingham, $\mathrm{ME}$ ) and transferred to a Plexiglas recording chamber (1.5 $\mathrm{ml}$ volume) on the fixed stage of an Olympus BX50WI scope. The slice was kept in place with a grid and maintained at $33 \pm 0.5^{\circ} \mathrm{C}$. One to two hours later the slice was used for recording. The chamber was continuously perfused with normal ACSF at a rate of $1-2 \mathrm{ml} / \mathrm{min}$.

Fluorescence and infrared imaging. Infrared, differential interference contrast imaging (IR-DIC) (Dodt and Zieglgansberger, 1990; Stuart et al., 1993) was performed to visualize neurons for extracellular or patchclamp recording using an Olympus Optical BX-50 microscope equipped with a $60 \times$ water immersion objective (numerical aperture, 0.9; Olympus). Images were detected with a CCD-300-RC camera (DAGE-MTI, Michigan City, IN) and displayed on a standard black and white video monitor (DAGE-MTI, HR 120). The images were transferred to the hard disk of a personal computer using an LG-3 scientific frame grabber (Scion Image, Frederick, MD) and processed further with Adobe Photoshop. Cy3-192IgG-labeled and rhodamine-labeled neurons were visualized using the appropriate fluorescence filters, as was Lucifer yellow. A neuron viewed with infrared optics was considered to be the same as that viewed with fluorescence optics when the infrared image and the fluorescent image of the neuron had the same position and orientation with the two imaging systems.

Electrophysiology recordings. The image of the cells in the slice was displayed on a video monitor, and glass pipettes used for electrophysiological recordings were visually advanced through the slice to the surface of the cell from which recordings were made. Extracellular recordings were performed with glass micropipettes filled with $2 \mathrm{M} \mathrm{NaCl}(5-10 \mathrm{M} \Omega$ ). Whole-cell patch-clamp recordings were performed using previously described methods (Alreja and Liu, 1996). In brief, low-resistance (2.5$3.5 \mathrm{M} \Omega$ ) patch pipettes were filled with a solution containing (in $\mathrm{mM}$ ): $\mathrm{K}$ methylsulfonate/ $\mathrm{KCl}, 120$; HEPES, 10; BAPTA $\mathrm{K}_{4}$, 5; sucrose, 20; $\mathrm{CaCl}_{2}, 2.38 ; \mathrm{MgCl}_{2}, 1 ; \mathrm{K}_{2} \mathrm{ATP}, 1$ and GTP, 0.1, pH 7.32-7.35. All recordings were made using an Axoclamp-2B amplifier (Axon Instruments, Foster City, CA) in the bridge mode; the output signal was filtered at $10 \mathrm{kHz}$. The cells selected for study had spike amplitudes of 70-100 $\mathrm{mV}$. Spike durations were measured at half-spike amplitude. In spontaneously firing cells these measurements were done at the resting potential and in quiescent cells, firing was evoked by injecting a small amount of depolarizing current. Voltage-clamp recordings were performed using the continuous single-electrode voltage-clamp mode. The firing rate, current, and voltage signals were amplified and continuously recorded on a chart recorder (Gould 2200). For intracellular labeling studies, Lucifer yellow $(1 \%)$ was added to the patch pipette solution.

Double-labeling studies. To determine the phenotype of cells recorded with Lucifer yellow-containing patch pipette solutions, double-labeling studies were performed on slices fixed using $4 \%$ paraformaldehyde solution. For the ChAT immunoreaction, the sections were incubated in a rat anti-ChAT primary antibody (1:5 dilution in PB; Boehringer Mannheim) overnight at room temperature. Subsequently, sections were incubated in rabbit anti-rat IgG, Texas Red-labeled (1:100 in PB; Vector Laboratories) for $2 \mathrm{hr}$ at room temperature in the dark.

Materials. Acetylcholine chloride, muscarine chloride, atropine sulfate, and (-)-scopolamine hydrobromide were obtained from Research Biochemicals (Natick, MA). All drugs were diluted in ACSF from previously prepared stock solutions that were prepared in water and stored at $-20^{\circ} \mathrm{C}$. Rhodamine microspheres were obtained from Lumafluor (Naples, FL), and Cy3-192IgG was custom-synthesized by Advanced Targeting Systems (San Diego, CA).

\section{RESULTS \\ Muscarinic agonists excite retrogradely labeled septohippocampal neurons}

As mentioned above, antidromically activated SHNs have been shown to be excited by muscarinic receptor agonists both in vivo (Dutar et al., 1983; Lamour et al., 1984) and in vitro in a concentration-dependent and atropine-sensitive manner (Liu et al., 1998). The phenotype of the excited neurons, while presumed to be cholinergic, has actually never been confirmed (Lamour et al., 1984). Before initiating studies on identified septohippocampal cholinergic neurons, we used a second technique, the technique of retrograde labeling to confirm the effects of muscarine on unidentified SHNs. Extracellular recordings were performed in retrogradely marked SHNs in rat brain slices prepared from rats in which the retrograde tracer, rhodamine microspheres, was injected directly into the rat hippocampus (Fig. 1A). ACh (1 mM) and/or muscarine $(1-10 \mu \mathrm{M})$ produced a profound excitatory effect in 8 of 13 SHNs tested (Fig. $1 B$ ), which resulted in a $31-300 \%$ increase in firing rate (mean, $138 \pm 42 \%$ ). These 

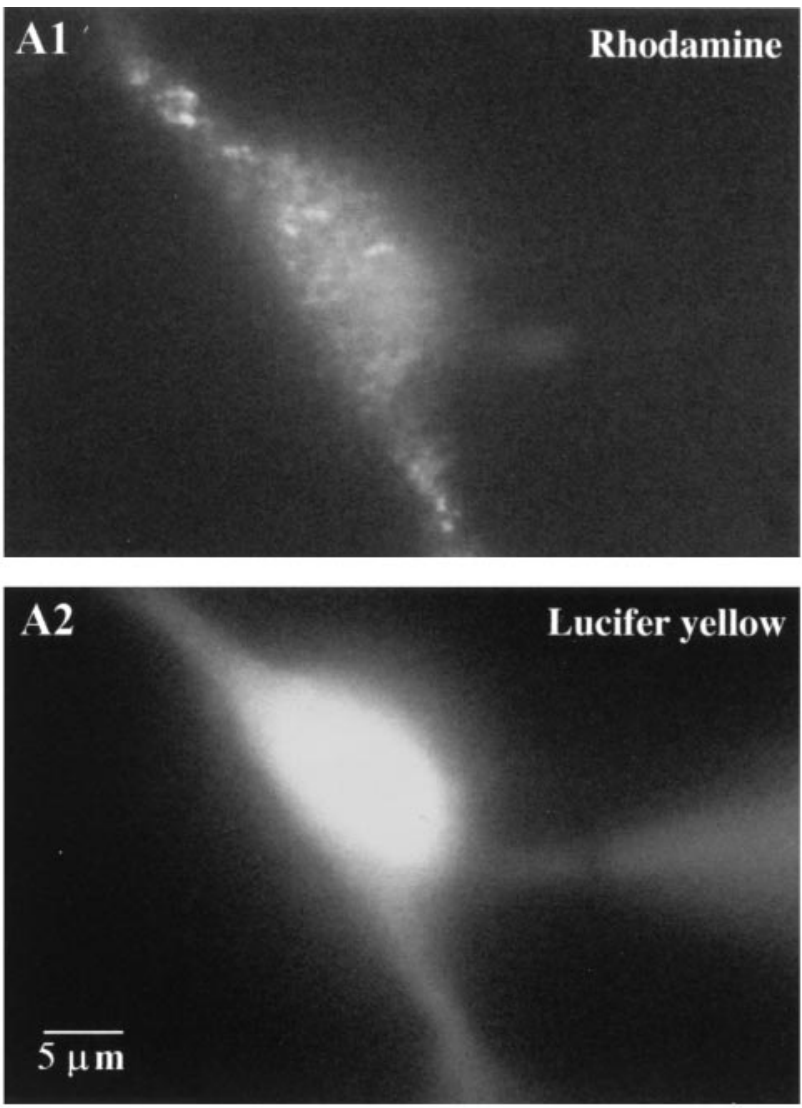

B

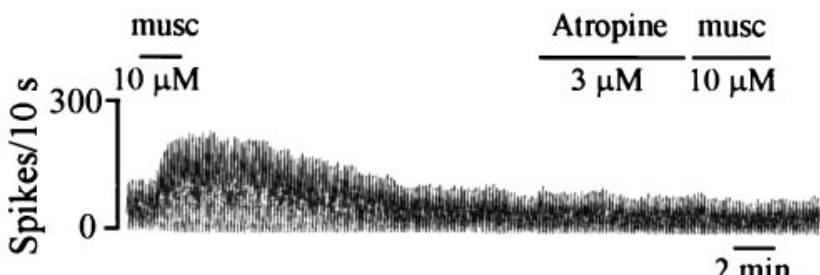

Figure 1. Retrogradely labeled rat septohippocampal neurons are excited by the muscarinic cholinergic receptor agonist muscarine. $A 1$ shows an SHN that was retrogradely labeled using rhodamine beads. $A 2$, The cell was filled with Lucifer yellow during an in vitro whole-cell recording. Note the patch pipette in the right side of the field. $B$, Chart record shows that a near-maximal concentration (Liu and Alreja, 1997) of bath-applied muscarine (musc) produces a profound and prolonged increase in firing rate in an SHN. Atropine, a muscarinic receptor antagonist, rapidly blocked the response to a subsequent application of muscarine; a high concentration of atropine was used primarily to get a rapid block. Lower concentrations (100 nM) also block ACh-muscarine responses, albeit, with a slower time course.

neurons had basal firing rates of $9.1 \pm 2.2 \mathrm{~Hz}$ (range, 2-19 Hz); $\mathrm{ACh} /$ muscarine produced a statistically significant increase in rate $(p<0.001$; mean, $16.3 \pm 2.5 \mathrm{~Hz}$; range, $8-25 \mathrm{~Hz})$. Four of 13 SHNs tested in this study did not respond to muscarine, and one was inhibited by muscarine. All effects of ACh-muscarine were blocked by the muscarinic receptor antagonist atropine (100 nM to $3 \mu \mathrm{M})$. As expected, both the lower and the higher concentrations of the antagonists blocked the $\mathrm{ACh}$-muscarine responses; the higher concentrations however, had a much more rapid effect. These observations thus confirm earlier studies that have
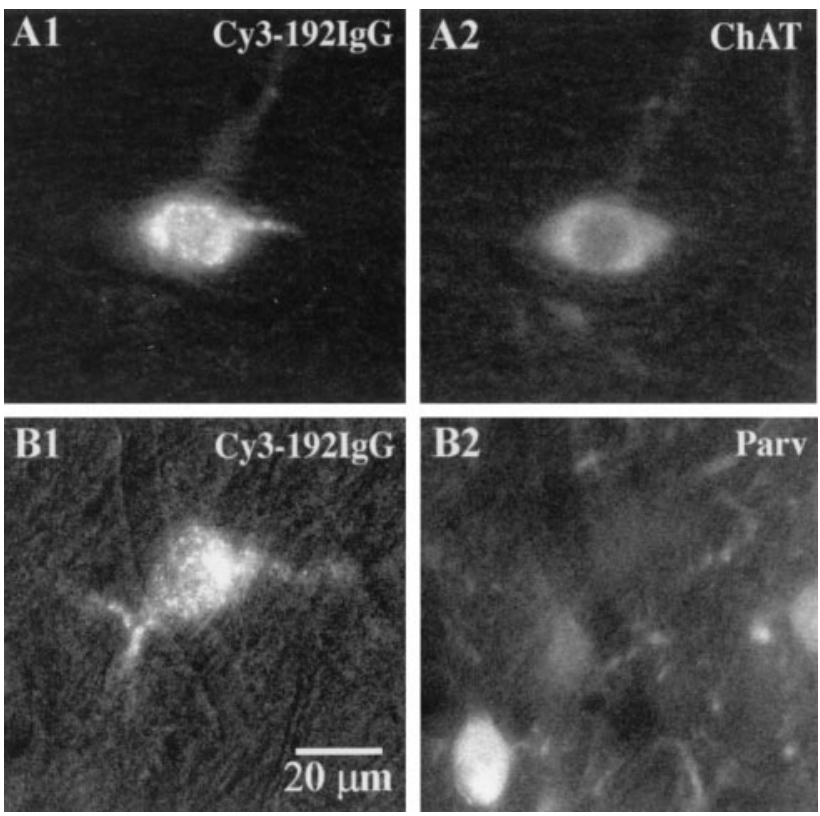

Figure 2. Double-labeling studies confirm that Cy3-192IgG selectively labels septohippocampal cholinergic and not GABAergic neurons. $A$ shows a Cy3-192IgG-retrogradely labeled neuron $(A 1)$ that is ChATpositive $(A 2)$ and therefore confirmed to be cholinergic. $B$ shows a Cy3-192IgG-labeled neuron (B1) that does not colocalize the calciumbinding protein parvalbumin (B2; Parv), a marker of septohippocampal GABA neurons. Note that a parvalbumin-positive neuron in the same field is not labeled with $\mathrm{Cy} 3-192 \mathrm{IgG}$.

reported the presence of muscarine-excited MSDB neurons that project to the hippocampus.

\section{Cy3-192lgG selectively labels septohippocampal cholinergic neurons in the MSDB}

To test the effect of muscarine on identified septohippocampal cholinergic neurons, we injected rats, intraventricularly, with the novel fluorescent marker, Cy3-192IgG. Cy3-192IgG selectively labels septohippocampal cholinergic neurons in the MSDB (Hartig et al., 1998).

Before initiating electrophysiological recordings, we performed double-labeling studies to confirm the selectivity of Cy3-192IgG as a marker for cholinergic neurons in the MSDB. Two to five days after unilateral or bilateral intraventricular injections of Cy3-192IgG, retrogradely labeled, red-fluorescent neurons could be observed in the MSDB. Consistent with published findings, Cy3-192IgG-labeled MSDB neurons were found to colocalize the enzyme ChAT, a well established marker of cholinergic neurons (Fig. 2A); all cholinergic neurons however did not get labeled with Cy3-192IgG, presumably because of incomplete diffusion of Cy3-192IgG (Hartig et al., 1998). In addition, we performed double-labeling studies using an antibody against the calciumbinding protein parvalbumin. In the MSDB, parvalbumin is selectively contained in septohippocampal GABA neurons (Freund, 1989). We found that parvalbumin-positive neurons never colocalized Cy3-192IgG (Fig. 2B). As expected, Cy3192IgG -labeled neurons also did not colocalize the enzyme glutamic acid decarboxylase (GAD); which is expressed both by local as well as by projection GABAergic neurons (data not shown). Thus, the selectivity of Cy3-192IgG for cholinergic neurons is similar to that reported for the well-established immunotoxin 192IgG-saporin (Wenk et al., 1994; Wiley et al., 1995). 

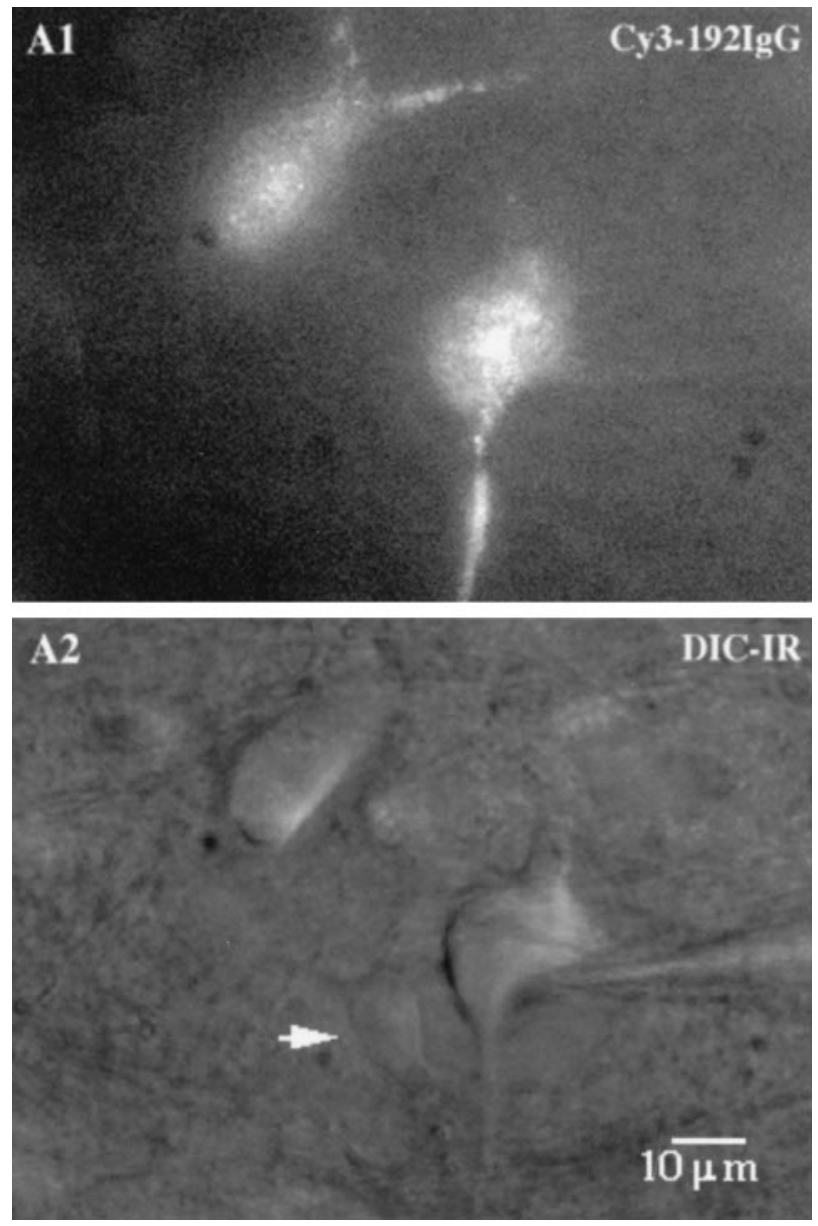

Figure 3. Visualization of septohippocampal cholinergic neurons in live rat brain slices using Cy3-192IgG, a selective marker of p75-receptorexpressing neurons in the MSDB. A, Cy3-192IgG-labeled neurons show a granular fluorescent labeling as seen in a $300-\mu \mathrm{m}$-thick slice preparation. $B$, The same neurons visualized using differential interference contrast, infrared videomicroscopy. Note an unlabeled neuron (arrow) and the healthy appearance of the labeled cells.

Therefore, although the Cy3-192IgG-labeled neuronal population in the MSDB is exclusively cholinergic, the unlabeled population although primarily GABAergic (local and projection), also includes unlabeled cholinergic neurons. With these findings in view, we tested the effects of muscarinic agonists on both Cy3-192IgG-labeled and unlabeled neurons.

\section{Muscarine does not excite Cy3-192lgG-labeled MSDB neurons but profoundly excites unlabeled MSDB neurons}

Extracellular and whole-cell recordings were made from $\mathrm{Cy} 3-$ 192IgG-labeled and unlabeled MSDB neurons visualized in rat brain slices using an IR-DIC videomicroscope equipped with appropriate filters for visualization of fluorescence. Cy3-192IgGlabeled neurons appeared as red fluorescent neurons with a punctate-type staining (Fig. 3), presumably because of clustering of the red fluorescent antibodies in compartments resembling lysosomes (Hartig et al., 1998). Cy3-192IgG-labeled neurons had a healthy appearance (Fig. 3); $43 \%$ of the neurons from which we recorded $(n=53)$ fired spontaneously at a rate of $2 \pm 0.07 \mathrm{~Hz}$ recorded extracellularly. Whole-cell recordings were also established in 37 of 53 neurons tested. These neurons exhibited elec- trophysiological characteristics similar to those described for cholinergic neurons using double-labeling techniques by previous workers (see below).

The effect of ACh and/or the muscarinic receptor agonist, muscarine $(1-10 \mu \mathrm{M})$ was tested in a total of $47 \mathrm{Cy} 3$-labeled neurons. Surprisingly, none of the Cy3-192IgG-labeled neurons tested were excited by $\mathrm{ACh}$-muscarine, although they were strongly excited by the excitatory amino acid glutamate $(n=18$; data not shown). Instead, muscarine produced inhibitory responses (Fig. 4A) in 62\% (29 of 47) of the Cy3-labeled neurons (1-10 mV hyperpolarization; mean, $3.5 \pm 0.6 \mathrm{mV}$ ). The remaining $38 \%$ neurons were not affected by muscarine.

In sharp contrast to the effects of $\mathrm{ACh}$-muscarine on Cy3192IgG-labeled neurons, $91 \%$ of the unlabeled neurons (31 of 34) were profoundly excited by ACh-muscarine (Fig. 4B) and showed a $19-600 \%$ increase in firing rate (mean, $192 \pm 36 \%$ ). These neurons had basal firing rates of $4.2 \pm 0.5 \mathrm{~Hz}$ (range, 0.6-11.5 Hz); ACh-muscarine produced a statistically significant increase in rate $(p<0.001$; mean, $11.3 \pm 0.9 \mathrm{~Hz}$; range, 1.7-25 $\mathrm{Hz}$ ). Two neurons were not affected by $\mathrm{ACh}-$ muscarine, whereas one neuron was inhibited. These data are summarized in Figure 4, $C$ and $D$. Consistent with previous observations, repeated applications of ACh-muscarine had a similar effect and did not show any desensitization (Liu et al., 1998).

All effects of ACh-muscarine, both excitatory and inhibitory, in labeled and unlabeled neurons, were blocked by the muscarinic receptor antagonists, atropine, or scopolamine (100 nM to $3 \mu \mathrm{M}$; $n=8)$.

Thus, the sampled Cy3-192IgG neuronal population discussed above, which is exclusively cholinergic, was found never to be excited by muscarine. This raises an important issue: if the septohippocampal neurons that are excited by muscarine are not cholinergic, then what is their phenotype? As mentioned before, a subpopulation of GABA neurons in the MSDB also projects to the hippocampus via the fimbria-fornix.

\section{Muscarine-excited MSDB neurons are noncholinergic, septohippocampal GABA-type}

The GABA neurons that project to the hippocampus from the MSDB are distinct from other neurons in the MSDB (cholinergic and local GABA) in that they exclusively express the calciumbinding protein parvalbumin (Freund, 1989). Because of this unique property, parvalbumin has become a well established marker of septohippocampal GABA neurons in the MSDB (Gao et al., 1995; Leranth and Vertes, 1999). Parvalbumin-containing neurons in the cortex (Kawaguchi and Kubota, 1997), hippocampus (Sik et al., 1995), and more recently in the MSDB (Morris et al., 1999), have been shown to possess unique spiking properties, such as a lack of spike frequency accommodation and thus an ability to fire rapidly; properties that may be reflective of the calcium-buffering properties of parvalbumin. Additionally, in the MSDB, parvalbumin-positive neurons have been reported to be spontaneously firing, possess short duration spikes (0.3-0.7 msec), and exhibit a depolarizing sag in response to a hyperpolarizing current.

To determine if muscarinic agonists excite MSDB neurons possessing electrophysiological characteristics of parvalbuminpositive neurons (and therefore of septohippocampal GABAtype neurons), we performed whole-cell recordings in brain slices taken from noninjected rats and noted the effect of muscarinic agonists on MSDB neurons that clearly exhibited the abovementioned electrophysiological criteria of parvalbumin-positive neu- 


\section{A Cy3-192IgG-labeled neuron}
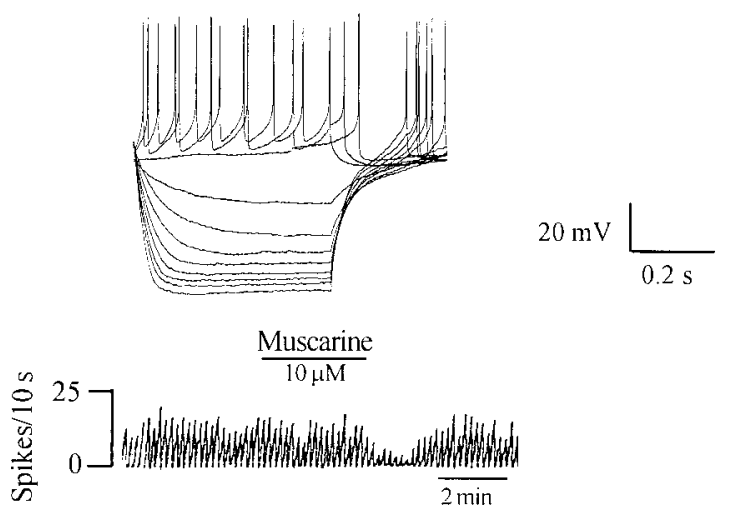

B Unlabeled neuron
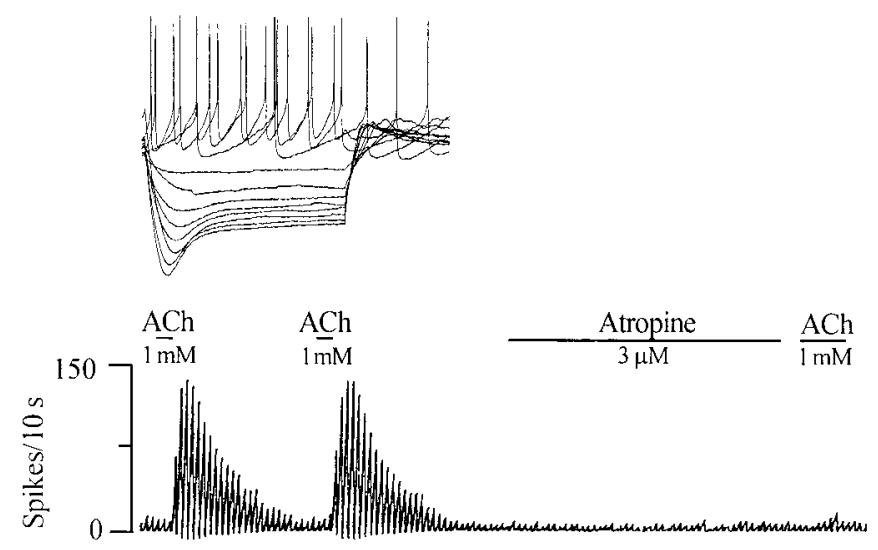

C

D
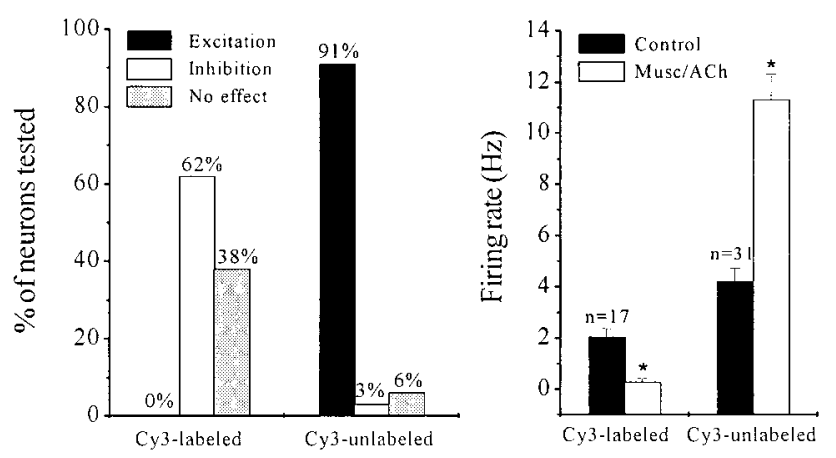

Figure 4. Cy3-192IgG-labeled neurons are not excited by muscarine, but unlabeled neurons are strongly excited by muscarine. $A$, Response of a Cy3-192IgG-labeled neuron to depolarizing and hyperpolarizing current steps (step size, $0.02 \mathrm{nA}$; maximum step, $+0.04 \mathrm{nA}$ ). Note the presence of inward rectification that is characteristic of cholinergic neurons. Chart record shows that this spontaneously firing neuron $(2 \mathrm{~Hz})$ responded to muscarine with a $80 \%$ decrease in firing rate. Inhibitory responses were observed in $\sim 60 \%$ of $\mathrm{Cy} 3-192 \mathrm{IgG}-$ labeled neurons, none of the neurons were excited by muscarine. $B$ shows the response of an unlabeled MSDB neuron that responded to $\mathrm{ACh}$, with a $600 \%$ increase in firing rate. Note that a second application of $\mathrm{ACh}$ produced a similar response; the excitatory effect was rapidly blocked by the muscarinic receptor antagonist atropine, which was used at a high concentration in this cell so as to get a fast blockade of the ACh response. Similar excitatory responses to $\mathrm{ACh}$-muscarine were observed in $91 \%$ of the unlabeled neurons tested. Also note the different electrophysiological profile of this neuron as rons. Of the 16 MSDB neurons so characterized, 14 were found to respond to muscarinic agonists with a profound excitation (Fig. $5 A$ ). These neurons had basal firing rates of $5.6 \pm 1 \mathrm{~Hz}$ (range, 1-18 Hz), which increased to $17-25 \mathrm{~Hz}$ after application of muscarine $(p<0.001 ; n=5)$. One neuron was inhibited by muscarine. In eight neurons, the effect of muscarine was tested under voltage clamp at a holding potential of $-60 \mathrm{mV}$, muscarine produced a 50-80 pA inward current in the eight neurons tested (mean, $52.5 \pm 0.7 \mathrm{pA}$; data not shown). Thus, similar to unlabeled neurons above, muscarinic agonists were found to excite a vast majority of parvalbumin-type MSDB neurons (87.5\%).

Again, in contrast, to the parvalbumin-containing, septohippocampal GABA-type neurons, neurons exhibiting electrophysiological properties of cholinergic-type neurons (also recorded from slices taken from noninjected rats), were found never to be excited by muscarine. Cholinergic-type neurons in uninjected rats therefore responded to muscarine in a manner similar to the Cy3-192IgG-labeled population described above. Whereas 10 of $16(62.5 \%)$ cholinergic-type neurons were inhibited by muscarine (1-10 $\mathrm{mV}$ hyperpolarization), the remaining six neurons were not affected by muscarine (Fig. $5 B$ ). Sixty percent of the neurons were spontaneously firing (range, $0.1-2 \mathrm{~Hz}$; mean, $1.2 \pm 0.2 \mathrm{~Hz}$ ). The electrophysiological criteria used for identification of cholinergictype MSDB neurons included the presence of a prolonged spontaneous afterhyperpolarization (200-700 msec) after a single spike and presence of anomalous rectification but no depolarizing sag in response to hyperpolarizing pulses; these criteria were based on those described by earlier workers (Griffith and Matthews, 1986; Markram and Segal, 1990; Gorelova and Reiner, 1996). The data on cholinergic-type and parvalbumin-type neurons is summarized in Figure 5, $C$ and $D$.

The effect of the muscarinic agonist was also tested in presence of tetrodotoxin (TTX). Whereas the excitatory response to muscarine persisted in presence of TTX in all six neurons tested, the inhibitory response in cholinergic-type neurons was blocked by TTX in two of five neurons tested (data not shown). In both these neurons the TTX-sensitive muscarinic inhibition was accompanied by an increase in the frequency of inhibitory synaptic activity, which is both TTX- and bicuculline-sensitive (Kumar et al., 1997). Thus, cholinergic-type neurons in the MSDB exhibited both direct postsynaptic as well as indirect inhibitory responses.

To further confirm the noncholinergic phenotype of the neurons excited by muscarine, we labeled MSDB neurons with Lucifer yellow during whole-cell recordings and, after completion of the experiment, we performed double-labeling studies using an antibody against the enzyme ChAT, which is a well established marker of cholinergic neurons. Of the eight successfully doublelabeled neurons, five were excited by muscarine, and the remaining three were not affected. Interestingly, the five neurons that were excited by muscarine were all found to be ChATimmunonegative, supporting the above findings that suggested that the neurons excited by muscarine are noncholinergic. All the

\section{$\leftarrow$}

compared to the Cy3-192IgG-labeled neuron shown above. Specifically, note the presence of a depolarizing sag in response to hyperpolarizing pulses (step size, $0.02 \mathrm{nA}$; maximum step, $+0.04 \mathrm{nA}$ ). $C$, Bar chart summarizes the effect of muscarine on Cy3-labeled and unlabeled neurons. Note that although none of the Cy3-labeled neurons were excited by muscarine, $91 \%$ of unlabeled neurons responded to the agonists with an excitation. $D$, Bar chart shows that whereas muscarine produced a significant decrease in firing rate in Cy3-labeled neurons, it produced an increase in rate in unlabeled neurons. 
A1 Parvalbumin-type neuron

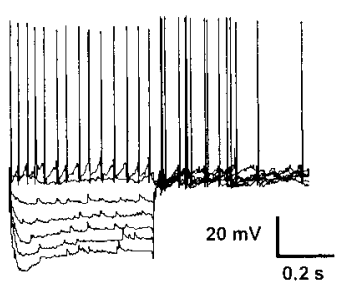

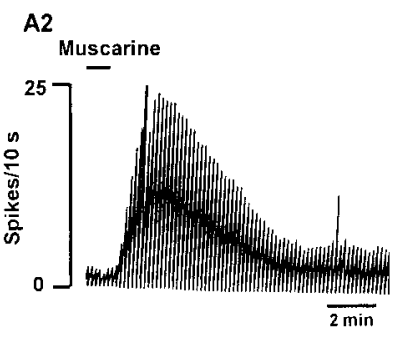

B Cholinergic-type neuron

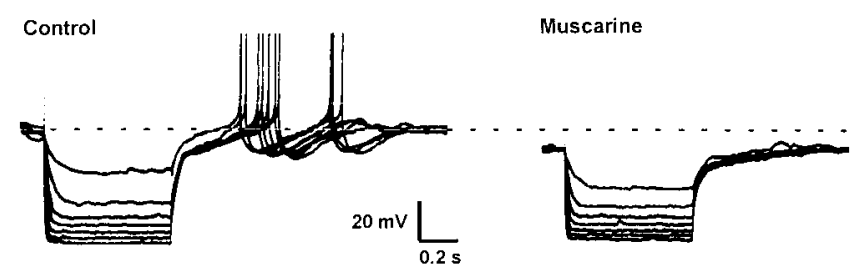

C

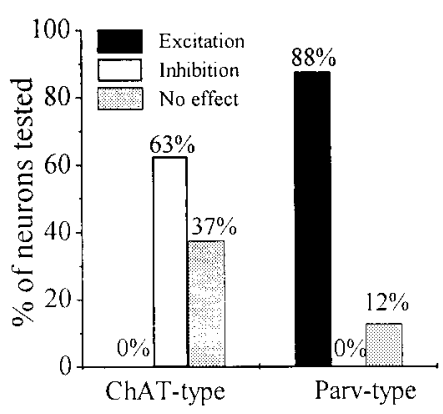

D

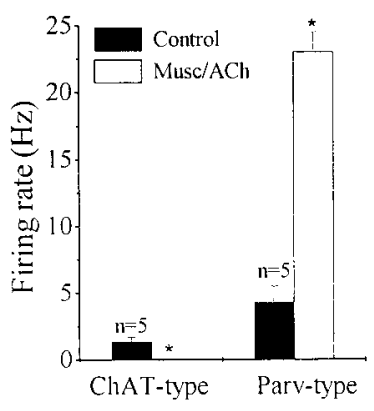

Figure 5. Septohippocampal GABA-type but not cholinergic-type neurons rats are excited by muscarine. $A$, These whole-cell recordings were performed in brain slices taken from uninjected rats. Neurons were classified as septohippocampal cholinergic-type or GABA-type based on electrophysiological characteristics (see Results). A1 shows a fast-spiking, nonaccommodating, GABA-type MSDB neuron. A2, Chart recording from the same neuron shows the profound excitatory effect of bathapplied muscarine. An excitatory effect was observed in $87.5 \%$ of septohippocampal GABA-type neurons tested. Note the depolarizing sag in response to the hyperpolarizing pulses and the presence of an anodebreak excitation after termination of the hyperpolarizing pulses. $B$, Whole-cell recording from a spontaneously firing cholinergic-type MSDB neuron. This cell exhibited a prominent slow afterhyperpolarization after a spike and strong inward rectification in response to hyperpolarizing pulses. Bath-applied muscarine $(10 \mu \mathrm{M}, 2 \mathrm{~min})$ produced a $9 \mathrm{mV}$ hyperpolarization that reversed after washout (washout not shown). Inhibitory effects of muscarine were observed in $62.5 \%$ of cholinergic-type MSDB neurons. $C$, Bar chart summarizes the effect of muscarine on cholinergicand parvalbumin-type MSDB neurons. Note that although none of the ChAT-type neurons were excited by muscarine, $88 \%$ of Parv-type neurons responded to the agonists with an excitation. $D$, Bar chart shows that whereas muscarine produced a significant decrease in firing rate in ChATtype neurons, it produced an increase in rate in Parv-type neurons.

ChAT-immunonegative neurons had electrophysiological properties similar to those that have been described for septohippocampal GABA neurons (see above). Of the three neurons that were not affected by muscarine, one colocalized ChAT, and two were ChAT-immunonegative.

In conclusion, septohippocampal cholinergic neurons were never found to be excited by muscarine, whereas noncholinergic, septohippocampal GABA-type neurons were profoundly excited by muscarine.

\section{DISCUSSION}

The main findings of this study are: (1) muscarinic receptor agonists do not excite septohippocampal cholinergic neurons, and (2) noncholinergic, septohippocampal GABA-type MSDB neurons are strongly excited by muscarinic agonists. These findings, therefore, challenge the current belief that MSDB cholinergic neurons are excited by their own neurotransmitter and that this excitation and the subsequent increase in hippocampal ACh underlies the improvement in learning and memory that is observed after intraseptal administration of muscarinic drugs.

\section{Muscarinic agonists do not excite septohippocampal cholinergic neurons}

Using a fluorescent labeling technique, involving the p75receptor antibody conjugated to the $\mathrm{Cy} 3$ fluorochrome for selective visualization of septohippocampal cholinergic neurons located in the MSDB, we have found no excitatory effects of muscarine on Cy3-192IgG-labeled septohippocampal cholinergic neurons. In fact, Cy3-labeled septohippocampal cholinergic neurons are either inhibited or not affected by muscarine. Recordings from cholinergic-type MSDB neurons (in brain slices prepared from noninjected rats), classified according to previously published electrophysiological criteria, also yielded the same results. Therefore, the presence of Cy3-192IgG in septohippocampal cholinergic neurons does not appear to alter their responsivity to muscarinic agonists. The electrophysiological properties of $\mathrm{Cy3}-$ labeled neurons were also similar to those of cholinergic-type neurons recorded from noninjected rats, suggesting that $\mathrm{Cy} 3-$ 192IgG may be a useful tool worthy of being exploited for future studies on septohippocampal cholinergic neurons as well as on p75 receptor-expressing neurons elsewhere in the brain, such as in the nucleus basalis.

The finding that septohippocampal cholinergic neurons are not excited by muscarine is very interesting because intaseptal injections of muscarinic agonists elicit continuous hippocampal theta rhythm and produce behavioral improvements in working and memory tasks both in young and aged rats (see introductory remarks). Our results indicate that the mechanisms underlying intraseptal muscarinic agonist-induced improvements in learning and memory and production of theta rhythm do not involve an impulse-dependent increase in hippocampal ACh release. This conclusion is supported by the findings of microdialysis studies that show that infusions of muscarinic agonists into the MSDB produce a dose-dependent decrease in hippocampal ACh release (Gorman et al., 1994) or have no effect (Moor et al., 1995). A decrease in hippocampal ACh release would be predicted by the results of the present study because $60-65 \%$ of septohippocampal cholinergic neurons from which we recorded were found to be inhibited by muscarine.

The finding that a subpopulation of septohippocampal cholinergic neurons is inhibited by muscarine is consistent with lightmicroscopic colocalization studies that have demonstrated the presence of $\mathrm{m} 2$ receptor immunoreactivity (a muscarinic receptor associated with inhibitory responses) in a subset of choline acetyltransferase-immunoreactive as well as noncholinergic neurons (Van der Zee and Luiten, 1994; Levey et al., 1995) and retrogradely labeled septohippocampal neurons (Rouse and Levey, 1996). m2 receptor mRNA has also been shown to colocalize with cholinergic MSDB neurons (Vilaro et al., 1992). 


\section{Muscarinic agonists excite noncholinergic, septohippocampal GABA-type neurons}

The finding that muscarinic agonists do not have any excitatory effects on septohippocampal cholinergic neurons raises the question of what cellular mechanism or mechanisms might mediate the effects of intraseptal muscarinic drugs on learning and memory and the associated theta rhythm. The results of the present study as well as previously published studies clearly show that muscarine-excited MSDB cells do project to the hippocampus (Dutar et al., 1983; Lamour et al., 1984; Liu et al., 1998), suggesting then that the muscarine-excited neurons must then be GABAergic. As mentioned previously, similar to the cholinergic neurons, the septohippocampal GABA neurons also project to the hippocampus via the fimbria-fornix. In fact, in our earlier study using the technique of antidromic activation, we found that septohippocampal neurons excited by muscarine had fastconducting fibers, with conduction velocities greater than $1 \mathrm{~m} / \mathrm{sec}$, which may be suggestive of GABA neurons (Liu et al., 1998).

In the present study, muscarinic agonists consistently produced a strong excitation of unlabeled neurons in Cy3-192IgG-injected rats, some of which were confirmed to be noncholinergic using the technique of double labeling. Because Cy3-192IgG does not label parvalbumin-positive or GAD-positive neurons of the MSDB, it is likely that the unlabeled cell population, which was profoundly excited by muscarine, included the septohippocampal GABA neurons of the MSDB. Additionally, in uninjected rats a vast majority of neurons exhibiting electrophysiological properties characteristic of septohippocampal GABA-type neurons were profoundly excited by muscarine.

\section{Implications of the findings}

The present study suggests that an activation of septohippocampal GABA neurons and not septohippocampal cholinergic neurons may underlie the behavioral and electrophysiological effects observed after intraseptal inf usions of muscarinic agonists in rats. Whereas most published research has focused on the importance of septohippocampal cholinergic mechanisms in learning and memory functions and in generation of the theta rhythm, the role of septohippocampal GABAergic mechanisms is being increasingly recognized, especially with regard to production of theta activity (Stewart and Fox, 1990; Bassant et al., 1995; Brazhnik and Fox, 1997, 1999; Monmaur et al., 1997). The results of the present study suggest that the reported effects of intraseptal carbachol on theta rhythm (Monmaur and Breton, 1991; Lawson and Bland, 1993) cannot be attributed to an increase in firing of septohippocampal cholinergic neurons. Therefore, the question is, how important are the cholinergic neurons for carbachol-induced generation of theta rhythm? Buzsaki's laboratory has demonstrated that intraseptal infusions of carbachol continue to elicit theta activity in the hippocampus even in the complete absence of MSDB cholinergic neurons in $192 \mathrm{IgG}$-saporin-treated rats, albeit, at a reduced amplitude, thereby indicating a critical role of septohippocampal GABAergic neurons in generation of theta rhythm (Lee et al., 1994).

Anatomically, the septohippocampal GABA neurons are well positioned to exert indirect but strong effects on hippocampal pyramidal neurons. In contrast to the septohippocampal cholinergic neurons, which innervate almost every type of neuron in the hippocampus (pyramidal cells, dentate granule cells, inhibitory interneurons) (Frotscher and Leranth, 1985), the septohippocampal GABA neurons selectively innervate only the GABA interneurons of the hippocampus (Freund and Antal, 1988). Via this very selective connectivity, the septohippocampal GABA neurons can theoretically produce a powerful disinhibitory effect on hippocampal pyramidal neurons. In fact, a recent study performed using a novel combined septohippocampal slice preparation has provided electrophysiological evidence that activation of septohippocampal GABAergic fibers can lead to a disinhibition of pyramidal cells (Toth et al., 1997). Therefore, it is conceivable that a profound muscarinic agonist-induced excitation of septohippocampal GABA neurons, as was observed in the present study, could, via hippocampal interneurons, produce a powerful disinhibition of pyramidal cells and possibly promote induction of long-term potentiation in the hippocampus. Long-term potentiation is preferentially induced when the pyramidal cells are maximally stimulated (Pavlides et al., 1988).

In addition to muscarinic agonists, serotonin, primarily via 5-HT $2 \mathrm{~A}$ receptors, (Alreja, 1996; Liu et al., 1997), and norepinephrine, via $\alpha_{1}$ receptors (Alreja and Liu, 1996), also excite septohippocampal GABA neurons, albeit, not as profoundly as muscarine. Opioids, on the other hand, via mu receptors, inhibit septohippocampal GABA neurons (Alreja et al., 2000). Interestingly, behavioral studies have reported that intraseptal infusions of opioids (Bostock et al., 1988; Ragozzino et al., 1992) or $\alpha_{1}$ noradrenergic receptor antagonists (Marighetto et al., 1989), treatments that would decrease impulse flow in the septohippocampal GABA pathway, impair learning and memory.

Pharmacologically, the excitatory effects of muscarinic agonists on septohippocampal neurons are mediated via non- $\mathrm{M}_{1}$ type muscarinic receptors $\left(\mathrm{M}_{3}\right.$ and possibly $\mathrm{M}_{5}$ subtypes) (Liu et al., 1998). Thus, muscarinic agonists directed toward the $M_{3}$ and $M_{5}$ receptor subtypes, could, theoretically by mimicking the behavioral effects of muscarine, alleviate age-related amnesia as agerelated amnesia, and decrease in theta power can be alleviated by intraseptal infusions of muscarinic agonists in rats (Markowska et al., 1995). If mechanisms similar to those that occur in aged rats also contribute to dementias associated with Alzheimer's, Parkinsonism, or even those associated with mental illnesses such as schizophrenia, then $\mathrm{M}_{3}$ and $\mathrm{M}_{5}$-receptor agonists could prove useful therapeutically.

\section{REFERENCES}

Alreja M (1996) Excitatory actions of serotonin on GABAergic neurons of the medial septum and diagonal band of Broca. Synapse 22:15-27.

Alreja M, Liu W (1996) Noradrenaline induces IPSCs in rat medial septal/diagonal band neurons: involvement of septohippocampal GABAergic neurons. J Physiol (Lond) 494:201-215.

Alreja M, Shanabrough M, Liu W, CL (2000) Opioids suppress IPSCs in neurons of the rat medial septum/diagonal band: involvement of septohippocampal GABAergic neurons. J Neurosci 20:1179-1189.

Apartis E, Poindessous-Jazat FR, Lamour YA, Bassant MH (1998) Loss of rhythmically bursting neurons in rat medial septum following selective lesion of septohippocampal cholinergic system. J Neurophysiol 79:1633-1642.

Bassant MH, Apartis E, Jazat-Poindessous FR, Wiley RG, Lamour YA (1995) Selective immunolesion of the basal forebrain cholinergic neurons: effects on hippocampal activity during sleep and wakefulness in the rat. Neurodegeneration 4:61-70.

Batchelor PE, Armstrong DM, Blaker SN, Gage FH (1989) Nerve growth factor receptor and choline acetyltransferase colocalization in neurons within the rat forebrain: response to fimbria-fornix transection. J Comp Neurol 284:187-204.

Benzi G, Moretti A (1998) Is there a rationale for the use of acetylcholinesterase inhibitors in the therapy of Alzheimer's disease? Eur J Pharmacol 346:1-13. 
Bland BH, Oddie SD (1998) Anatomical, electrophysiological and pharmacological studies of ascending brainstem hippocampal synchronizing pathways. Neurosci Biobehav Rev 22:259-273.

Bostock E, Gallagher M, King RA (1988) Effects of opioid microinjections into the medial septal area on spatial memory in rats. Behav Neurosci 106:643-652.

Brazhnik ES, Fox SE (1997) Intracellular recordings from medial septal neurons during hippocampal theta rhythm. Exp Brain Res 114:442-453.

Brazhnik ES, Fox SE (1999) Action potentials and relations to the theta rhythm of medial septal neurons in vivo. Exp Brain Res 127:244-258.

Brito GN, Brito LS (1990) Septohippocampal system and the prelimbic sector of frontal cortex: a neuropsychological battery analysis in the rat. Behav Brain Res 36:127-146.

Dickinson-Anson H, Aubert I, Gage FH, Fisher LJ (1998) Hippocampal grafts of acetylcholine-producing cells are sufficient to improve behavioural performance following a unilateral fimbria-fornix lesion. Neuroscience 84:771-781.

Dodt HU, Zieglgansberger W (1990) Visualizing unstained neurons in living brain slices by infrared DIC-videomicroscopy. Brain Res 537:333-336.

Dunnett SB, Low WC, Iversen SD, Stenevi U, Bjorklund A (1982) Septal transplants restore maze learning in rats with fornix-fimbria lesions. Brain Res 251:335-348.

Dutar P, Lamour Y, Jobert A (1983) Acetylcholine excites identified septo-hippocampal neurons in the rat. Neurosci Lett 43:43-47.

Freund T (1989) GABAergic septohippocampal neurons contain parvalbumin. Brain Res 478:375-381.

Freund TF, Antal M (1988) GABA-containing neurons in the septum control inhibitory interneurons in the hippocampus. Nature 336(6195):170-3.

Frotscher M, Leranth C (1985) Cholinergic innervation of the rat hippocampus as revealed by choline acetyltransferase immunocytochemistry: a combined light and electron microscopic study. J Comp Neurol 239:237-246

Gao B, Hornung JP, Fritschy JM (1995) Identification of distinct GABAA-receptor subtypes in cholinergic and parvalbumin-positive neurons of the rat and marmoset medial septum-diagonal band complex. Neuroscience 65:101-117.

Givens BS, Olton DS (1990) Cholinergic and GABAergic modulation of medial septal area: effect on working memory. Behav Neurosci 104:849-855.

Givens B, Olton DS (1994) Local modulation of basal forebrain: effects on working and reference memory. J Neurosci 14:3578-3587.

Givens B, Olton DS (1995) Bidirectional modulation of scopolamineinduced working memory impairments by muscarinic activation of the medial septal area. Neurobiol Learn Mem 63:269-276.

Givens B, Sarter M (1997) Modulation of cognitive processes by transsynaptic activation of the basal forebrain. Behav Brain Res 84:1-22.

Gorelova N, Reiner PB (1996) Role of the afterhyperpolarization in control of discharge properties of septal cholinergic neurons in vitro. J Neurophysiol 75:695-706.

Gorman LK, Pang K, Frick KM, Givens B, Olton DS (1994) Acetylcholine release in the hippocampus: effects of cholinergic and GABAergic compounds in the medial septal area. Neurosci Lett 166:199-202.

Griffith WH, Matthews RT (1986) Electrophysiology of AChE-positive neurons in basal forebrain slices. Neurosci Lett 71:169-174.

Hartig W, Seeger J, Naumann T, Brauer K, Bruckner G (1998) Selective in vivo fluorescence labelling of cholinergic neurons containing p75(NTR) in the rat basal forebrain. Brain Res 808:155-165.

Katz LC, Burkhalter A, Dreyer WJ (1984) Fluorescent latex microspheres as a retrograde neuronal marker for in vivo and in vitro studies of visual cortex. Nature 310:498-500.

Kawaguchi Y, Kubota Y (1997) GABAergic cell subtypes and their synaptic connections in rat frontal cortex. Cereb Cortex 7:476-486.

Kohler C, Chan-Palay V, Wu JY (1984) Septal neurons containing glutamatic acid decarboxylase immunoreactivity project to the hippocampal region in the rat brain. Anat Embryol 169:41-44.

Kumar A, Liu W, Alreja M (1997) Multiple actions of muscarine on rat septohippocampal neurons. Soc Neurosci Abstr 23:2021.

Lamour Y, Dutar P, Jobert A (1984) Septo-hippocampal and other medial septum diagonal band neurons: electrophysiological and pharmacological properties. Brain Res 309:227-239.
Lawson VH, Bland BH (1993) The role of the septohippocampal pathway in the regulation of hippocampal field activity and behavior: analysis by the intraseptal microinfusion of carbachol, atropine, and procaine. Exp Neurol 120:132-144.

Lee MG, Chrobak JJ, Sik A, Wiley RG, Buzsaki G (1994) Hippocampal theta activity following selective lesion of the septal cholinergic system. Neuroscience 62:1033-1047.

Leranth C, Vertes RP (1999) Median raphe serotonergic innervation of medial septum/diagonal band of broca (MSDB) parvalbumincontaining neurons: possible involvement of the MSDB in the desynchronization of the hippocampal EEG. J Comp Neurol 410:586-598.

Levey AI, Edmunds SM, Hersch SM, Wiley RG, Heilman CJ (1995) Light and electron microscopic study of $\mathrm{m} 2$ muscarinic acetylcholine receptor in the basal forebrain of the rat. J Comp Neurol 351:339-356.

Lewis PR, Shute CCD (1967) The cholinergic limbic system: projections to hippocampal formation, medial cortex nuclei of the ascending cholinergic reticular system and the subfornical organ and supra-optic crest. Brain 90:521-537.

Liu W, Alreja M (1997) Atypical antipsychotics block the excitatory effects of serotonin in septohippocampal neurons in the rat. Neuroscience 79:369-382.

Liu W, Kumar A, Alreja M (1998) Excitatory effects of muscarine on septohippocampal neurons: involvement of M3 receptors. Brain Res 805:220-233.

Marighetto A, Durkin T, Toumane A, Lebrun C, Jaffard R (1989) Septal alpha-noradrenergic antagonism in vivo blocks the testing-induced activation of septo-hippocampal cholinergic neurones and produces a concomitant deficit in working memory performance of mice. Pharmacol Biochem Behav 34:553-558.

Markowska AL, Olton DS, Givens B (1995) Cholinergic manipulations in the medial septal area: age-related effects on working memory and hippocampal electrophysiology. J Neurosci 15:2063-2073.

Markram H, Segal M (1990) Electrophysiological characteristics of cholinergic and non-cholinergic neurons in the rat medial septum-diagonal band complex. Brain Res 513:171-174.

Monmaur P, Breton P (1991) Elicitation of hippocampal theta by intraseptal carbachol injection in freely moving rats. Brain Res 544:150-155.

Monmaur P, Collet A, Puma C, Frankel-Kohn L, Sharif A (1997) Relations between acetylcholine release and electrophysiological characteristics of theta rhythm: a microdialysis study in the urethaneanesthetized rat hippocampus. Brain Res Bull 42:141-146.

Moor E, DeBoer P, Auth F, Westerink BH (1995) Characterisation of muscarinic autoreceptors in the septo-hippocampal system of the rat: a microdialysis study. Eur J Pharmacol 294:155-161.

Morris NP, Harris SJ, Henderson Z (1999) Parvalbuminimmunoreactive, fast-spiking neurons in the medial septum/diagonal band complex of the rat: intracellular recordings in vitro. Neuroscience 92:589-600.

Pavlides C, Greenstein YJ, Grudman M, Winson J (1988) Long-term potentiation in the dentate gyrus is induced preferentially on the positive phase of theta-rhythm. Brain Res 439:383-387.

Ragozzino ME, Parker ME, Gold PE (1992) Spontaneous alternation and inhibitory avoidance impairments with morphine injections into the medial septum. Attenuation by glucose administration. Brain Res 597:241-249.

Rouse ST, Levey AI (1996) Expression of $\mathrm{m}_{1}-\mathrm{m}_{4}$ muscarinic acetylcholine receptor immunoreactivity in septohippocampal neurons and other identified hippocampal afferents. J Comp Neurol 375:406-416.

Segal M (1986) Properties of rat medial septal neurones recorded in vitro. J Physiol (Lond) 379:309-330.

Serafin M, Williams S, Khateb A, Fort P, Muhlethaler M (1996) Rhythmic firing of medial septum non-cholinergic neurons. Neuroscience [Errata (1997) 77:611; (1997) 78:927-928] 75:671-675.

Sik A, Penttonen M, Ylinen A, Buzsaki G (1995) Hippocampal CA1 interneurons: an in vivo intracellular labeling study. J Neurosci 15:6651-6665.

Sim JA, Griffith WH (1991) Muscarinic agonists block a lateafterhyperpolarization in medial septum/diagonal band neurons in vitro. Neurosci Lett 129:63-68.

Sim JA, Griffith WH (1996) Muscarinic inhibition of glutamatergic transmissions onto rat magnocellular basal forebrain neurons in a thin-slice preparation. Eur J Neurosci 8:880-891.

Sobreviela T, Clary DO, Reichardt LF, Brandabur MM, Kordower JH, Mufson EJ (1994) TrkA-immunoreactive profiles in the central ner- 
vous system: colocalization with neurons containing $\mathrm{p} 75$ nerve growth factor receptor, choline acetyltransferase, and serotonin. J Comp Neurol 350:587-611.

Stewart M, Fox SE (1990) Do septal neurons pace the hippocampal theta rhythm? [see comments]. Trends Neurosci 13:163-168.

Stuart GJ, Dodt HU, Sakmann B (1993) Patch-clamp recordings from the soma and dendrites of neurons in brain slices using infrared video microscopy. Pflügers Arch 423:511-518.

Toth K, Freund TF, Miles R (1997) Disinhibition of rat hippocampal pyramidal cells by GABAergic afferents from the septum. J Physiol (Lond) 500:463-474.

Van der Zee EA, Luiten PGM (1994) Cholinergic and GABAergic neurons in the rat medial septum express muscarinic acetylcholine receptors. Brain Res 652:263-272.

Vilaro MT, Wiederhold KH, Palacios JM, Mengod G (1992) Muscarinic
M2 receptor mRNA expression and receptor binding in cholinergic and non-cholinergic cells in the rat brain: a correlative study using in situ hybridization histochemistry and receptor autoradiography. Neuroscience 47:367-393.

Wenk GL, Stoehr JD, Quintana G, Mobley S, Wiley RG (1994) Behavioral, biochemical, histological, and electrophysiological effects of 192 $\mathrm{IgG}$-saporin injections into the basal forebrain of rats. J Neurosci 14:5986-5995.

Whitehouse PJ, Price DL, Struble RG, Clark AW, Coyle JT, Delon MR (1982) Alzheimer's disease and senile dementia: loss of neurons in the basal forebrain. Science 215:1237-1239.

Wiley RG, Berbos TG, Deckwerth TL, Johnson EM Jr, Lappi DA (1995) Destruction of the cholinergic basal forebrain using immunotoxin to rat NGF receptor: modeling the cholinergic degeneration of Alzheimer's disease. J Neurol Sci 128:157-166. 